\title{
ESTUDANTES E AVALIAÇÃO DA UNIVERSIDADE: UM ESTUDO CONJUNTO BRASIL-PORTUGAL
}

\section{DENISE LEITE}

Programa de Pós-Graduação da Educação da Universidade

Federal do Rio Grande do Sul - UFRGS

dleite@ufrgs.br

\section{RUI SANTIAGO}

Secção de Ciências Sociais, Jurídicas e Políticas da Universidade de Aveiro santiago@csjp.ua.pt

\section{MARIA CECÍLIA LORÉA LEITE}

Faculdade de Educação da Universidade Federal de Pelotas mclleite@gmail.com

\section{MARIA ELLY HERZ GENRO}

Faculdade de Educação da Pontifícia Universidade Católica do Rio Grande do Sul maria.elly@terra.com.br

\section{ANA MARIA BRAGA}

Secretaria de Avaliação Institucional da UFRGS

anabraga@terra.com.br

\section{MARLIS POLIDORI}

Centro Universitário Metodista IPA - RS

mpolidori@ipametodista.edu.br

\section{CECILIA BROILO}

Curso de Pedagogia da Universidade do Vale do Rio dos Sinos

cecilib@unisinos.br

Este trabalho obteve apoio do Conselho Nacional de Desenvolvimento Científico e Tecnológico - CNPq - e da Fundação de Amparo à Pesquisa do Estado do Rio Grande do Sul - Fapergs - no Brasil, e do Instituto de Cooperação Científica e Tecnológica Internacional - ICCTI - em Portugal. Colaboraram neste estudo as doutorandas Glades Teresa Félix, Clarice Escott e Regina Celi Machado Pires e os bolsistas de Iniciação Científica do CNPq Luciano Ewald e Ana Beatriz Nunes ( I ${ }^{\text {a }}$ ase); Renata Machado e Giselle Osório Pelisolli (2a fase). 


\title{
CLAUDIA SARRICO \\ Secção de Ciências Sociais, Jurídicas e Políticas da Universidade de Aveiro sarrico@csjp.ua.pt
}

ISABEL SANTOS

Pró-Reitoria de Planejamento da UFRGS

belsan@ufrgs.br

\begin{abstract}
RESUMO
Este artigo trata da percepção dos estudantes sobre avaliação das universidades. Origina-se da segunda fase de estudo desenvolvido ao abrigo da cooperação internacional CNPq-ICCTI. Dele participaram 476 alunos de duas universidades públicas brasileiras e uma portuguesa. As respostas a um questionário com questões abertas foram organizadas em categorias segundo o seu significado, com apoio de dispositivo informático para análise de dados qualitativos, e permitiram entender que, em geral, os estudantes pesquisados reconhecem a importância dos processos de avaliação e formam seus próprios conceitos sobre o tema. Para os alunos brasileiros, a avaliação parece ter sentido de avaliação institucional. Para os estudantes portugueses, a avaliação parece ter um significado de avaliação institucional e da aprendizagem. As culturas estudantis de repúdio à avaliação única de uma prova nacional, no caso brasileiro, parecem ter influenciado suas percepções sobre formatos avaliativos. As culturas estudantis relativas à competitividade do mercado, no caso português, valorizaram a avaliação como regulação. Em ambos os casos, os estudantes destacaram tanto a legitimidade da avaliação para a sociedade e os sistemas educativos (cultura englobante) quanto para o cotidiano das universidades (cultura englobada).

AVALIAÇÃO INSTITUCIONAL - AVALIAÇÃO DA APRENDIZAGEM - UNIVERSIDADES ESTUDANTES
\end{abstract}

\section{ABSTRACT}

STUDENTS AND ASSESSMENT OF THE UNIVERSITY: A JOINT STUDY BRAZIL-PORTUGAL. This article addresses student perception of university assessment. It draws on evidence from the second stage of study promoted by the international cooperation between CNPq and ICCTI. In the study, 476 students from two public universities in Brazil and one university in Portugal were surveyed. The answers to an open-ended questionnaire were categorized according to their meaning, with the support of a computer-assisted qualitative data analysis software program. With this information, it was possible to understand that the students surveyed, in general, acknowledge the importance of the evaluation processes and formulate their own concepts to the subject. To Brazilian students, this assessment seems to be institutional. To Portuguese students, the assessment seems to consider both the institution as well as the learning process. In the Brazilian case, the student culture that repudiates the single assessment by means of one national examination seems to have influenced students' perceptions of assessment formats. In the Portuguese case, the student culture related to market competitiveness valued the assessment process as a means of regulation. In both cases, the students emphasized the legitimacy of the 
assessment both for society and education systems (encompassing culture) as well as for the daily life at universities (encompassed culture).

INSTITUTIONAL EVALUATION - LEARNING EVALUATION - UNIVERSITIES - STUDENTS

Ortigo descreve, analisa e compara as representações sociais de estudantes universitários brasileiros e portugueses sobre a avaliação das universidades. As culturas estudantis sobre a avaliação das universidades foram um dos temas do estudo conjunto Brasil e Portugal, intitulado Avaliação, auto-análise e gestão das universidades. A pesquisa foi realizada em três universidades, a Universidade Federal do Rio Grande do Sul - UFRGS - a Universidade Federal de Pelotas - UFPel - e a Universidade de Aveiro, em Portugal, com o propósito de entender e discutir os processos de avaliação e auto-avaliação institucional. Foram estudados os casos de avaliação desenvolvidos, os processos de gestão e a estrutura organizacional de cada instituição de ensino superior IES. Buscou-se, por meio de entrevistas com os gestores das comunidades universitárias, entender os processos efetivados. Outros objetivos fizeram parte do projeto original. Neste artigo, destacam-se os resultados da segunda fase da pesquisa, com ênfase nos dados da consulta aos estudantes, considerados o fiel da balança. Estando longe da tomada de decisão imediata que move os gestores, esperava-se que eles respondessem de forma livre sobre o que entendiam por avaliação, se a avaliação produzia melhorias e mudanças na universidade.

Em geral, os gestores das universidades e dos processos de avaliação institucional preocupam-se em ouvir os estudantes sobre o ensino e os docentes, tendo em vista o desenvolvimento de processos qualificadores das atividades centrais da universidade. Por isso pareceu-nos que seria uma falha não ouvir os estudantes sobre a avaliação das universidades e sobre as mudanças e melhorias a ela relacionadas.

Na literatura revisada, Leckey e Neill (200I) confirmam a importância de ouvir os estudantes sobre a qualidade das instituições, mas quando se pensa em questionar os estudantes e compreender suas atitudes e pontos de vista, observa-se que eles são chamados a manifestar-se sobre professores e ensino, ou somente ensino, ou ensino e investigação ou sobre cursos e sistemas acadêmicos. Vejam-se, por exemplo, os estudos de Powell, Hunt e Irving ( I 997); Jenkins et al. (1998); Boss e Tarnai (1999); Sander et al. (2000); Santhaman e Hicks 
(2002). Outros estudos investigam a forma pela qual os estudantes aprendem na universidade, a aprendizagem e seus resultados, incluindo o sucesso e o insucesso escolar e a evasão: Entwistle e Ramsden (1983); Leite (1990; 1992; 2002); Latiesa (1992); Brasil (1996); Tavares, Santiago e Lencastre (I 998); Oliveira (2000); Santiago et al. (200 I). Encontram-se ainda investigações sobre alguns aspectos de experiências educativas e participativas dos estudantes, atividades extra-curriculares, suas culturas e seu envolvimento (Feldman, Newcomb, 1976; Lizzio, Wilson, Simons, 2002; Bacelar, Fontes, 2003). No Brasil podemos citar a coletânea organizada por Mercuri e Polydoro (2003).

Observa-se que a pesquisa internacional tem feito um investimento importante nas culturas estudantis, com base nos estudos de Entwistle e Ramsden ( 1 983), que adotaram metodologias naturalistas procurando captar como os estudantes vêem a si próprios, aprendem e são avaliados na universidade. No Brasil, o tema ainda não teve o destaque devido. Estudantes e sua percepção sobre avaliação institucional das universidades parece ser um tema novo que não tem sido eleito de forma preferencial pelos investigadores das linhas que pesquisam universidade e educação superior. Em geral, os estudantes são chamados a dar sua opinião sobre as funções da universidade, mas é menos freqüente sua participação em estudos que se dedicam a compreender suas percepções sobre os processos de avaliação institucional. Desta forma, enfatizamos que:

....os estudantes são capazes de refletir sobre suas experiências institucionais e questionar os pressupostos e processos de avaliação das universidades. Sobretudo, questionar suas funções sociais e educativas, como instrumento de regulação interna das atividades das instituições ou como instrumento de regulação externa do sistema, nomeadamente dos mecanismos de mercado e da competição inter-institucional. (Genro et al., 2003, p.6)

De acordo com nossas hipóteses de trabalho as representações dos estudantes sobre a avaliação das universidades apresentariam tendência à valorização de processos de autonomia universitária; o impacto dos processos e resultados da avaliação institucional desenvolvida e a informação gerada fariam parte do repertório e das lógicas de entendimento desses atores; sua visão dos processos destacaria de forma crítica o que se passara, por dentro de cada curso que sofrera avaliações de diferentes formatos. Compreendemos que a expe- 
riência singular de cada universidade, por sua vez, poderia marcar as respostas. Da mesma forma, em cada país, tanto a condução da avaliação institucional quanto a da avaliação praticada em sala de aula poderiam fazer parte do repertório de respostas.

Neste texto, discutimos algumas hipóteses do trabalho e os resultados do estudo empírico. Na primeira secção, enunciamos parte da revisão da literatura. Na segunda, discutimos a metodologia e após, os resultados e sua interpretação.

\section{ESTUDANTES E UNIVERSIDADE: APRENDIZAGENS E REPRESENTAÇÕES}

Na universidade, tem-se como pressuposto que os estudantes aprendem. Espera-se que, após a passagem por um currículo estruturado e um certo número de anos de estudo e assistência a aulas e atividades, os estudantes adquiram competências, habilidades e saberes referentes a um campo de conhecimento, bem como o direito, após a colação de grau, de exercer uma profissão reconhecida como necessária pela coletividade. Este seria o papel central da universidade, o de preparar as novas gerações para o domínio de uma capacidade, de um conjunto de conhecimentos avançados que os prepararia para dinamizarem a sociedade do futuro e, assim, produzir e reproduzir sua existência. Para Habermas (1970) a universidade faz mais do que isso. Ela habilita os jovens na área de capacidades extra-funcionais e profissionais e ensina, transmitindo conhecimentos e saberes, para que venham a interpretar e desenvolver as tradições culturais de um povo ou nação. Ao fazê-lo, a universidade poderia também desenvolver a consciência social e política da juventude. Nesse caso, somem-se a essa aprendizagem o que se passa em sala de aula e nas entidades estudantis, e, também, o ambiente cultural do entorno universitário e das suas relações sociais e profissionais. Isso porque o estudante, oriundo de grupo familiar que se situa em uma determinada capa da estratificação social, dentro da instituição universidade, parece manifestar um status móvel, vindo a constituir-se como parte de uma categoria social transitória. Na universidade, o estudante seria um transindivíduo, expressão de Lucien Goldmann ( 1984 ), pois deixaria de ser um eu isolado para autoconstituir-se como um ser em relação, uma nova subjetividade em construção. Esta se faz dentro de um 
contexto bastante específico, no encontro e desencontro com outros sujeitos, colegas, professores, companheiros de atividades, de trabalho.

Nesse sentido, a aprendizagem de fatos, dados, conceitos, habilidades, competências, não ocorre sem a produção de uma consciência dessa aprendizagem, esperando-se que nos espaços de produção e reprodução gerados pela universidade também se forme uma consciência voltada para o social. Essa percepção foi investigada por Leite (1990; 2002), constatando que, ao ingressarem em seus cursos, os estudantes se consideravam interessados em aprender, porém, ao longo do tempo, apenas alguns, dentre aqueles que constituíam a amostra examinada, conseguiam estabelecer significados para suas aprendizagens. Estes estudantes eram capazes de reconhecer o conhecimento com o qual trabalhavam em seus cursos. Em um processo de meta-aprendizagem eles elaboravam representações sobre si como pessoa e sobre a sua identidade social como universitários e cidadãos. Desse ponto de vista, "o estudante é um ser de relações, um indivíduo na sua existência e um ser social na sua essência" (Leite, 1990, p.8).

A universidade exerce uma influência sobre o estudante que vai além do contato aprendiz-ensinante. Feldman e Newcomb (1976) reportam-se às culturas estudantis como um conjunto de entendimentos partilhados sobre o ambiente e um conjunto de ações congruentes para eles. As culturas estudantis compreenderiam valores, normas e orientações partilhadas pelos estudantes as quais fariam parte de uma capacidade ampla de resposta aos contextos e entornos universitários, um repertório de respostas coletivas ou individuais aos problemas percebidos.

Nosso grupo de pesquisa entendeu que as respostas dos estudantes sobre a avaliação das universidades seriam produto de uma aprendizagem compartilhada não formal, e se manifestariam como representações sociais ou elaborações coletivas. Nesse sentido, as representações dos sujeitos transindivíduos indicariam um esforço de adaptação ao contexto institucional e, também, uma necessidade de influenciar um contexto por meio das culturas estudantis.

\section{REPRESENTAÇÕES SOCIAIS}

As representações são produto de um conjunto de opiniões, informações, crenças, valores e atitudes expressas pelos sujeitos quando estes inter- 
pretam a realidade. As representações sociais são modos pelos quais, por meio das interações, o conhecimento é construído ou apropriado e esse processo se reflete na prática. As percepções dos atores acadêmicos são pertinentes para se entender as formas de agir na e sobre a instituição. Em verdade, não seriam a realidade objetiva, apesar de reportar-se a ela. As representações sociais indicariam posições subjetivas dos atores acadêmicos construídas por meio de processos sociais, de influências e aprendizagens partilhadas. Goffman (1989, p.29) explica melhor: "a representação é toda atividade de um indivíduo que se passa num período caracterizado por sua presença contínua diante de um grupo particular de observadores e que tem sobre estes alguma influência".

Pode-se imaginar que os estudantes, na condição de transindivíduos, desenvolvem, frente a outros atores, uma fachada, que segundo Goffman ( 1989 , p.29) é um desempenho que funciona regularmente, de forma geral e fixa, com o intuito de definir a situação para os que observam a representação, como os docentes, por exemplo, ou nós, os pesquisadores. Fachada, portanto, seria um "equipamento expressivo". Algo um tanto padronizado e intencional ou uma manifestação que pode ser inconscientemente empregada pelo sujeito quando ele é chamado a fazer a sua representação.

O autor explica pormenorizadamente o que seriam as partes padronizadas da "fachada":

- Cenário: inclui mobília e palco, ou seja, em nosso estudo, o contexto das diferentes universidades e países. Normalmente o cenário não muda. É o indivíduo que se coloca em determinada parte do cenário. Coloca-se de uma certa maneira, com uma certa aparência. Nesse estudo, como os estudantes se colocariam nos cenários de avaliação?

- Fachada pessoal: seria um distintivo da função ou da categoria, traduzindo-se pelo vestuário, sexo, idade, raça, altura, aparência, atitudes, padrões de linguagem, expressões faciais, gestos corporais. Nesse estudo, os estudantes apresentariam uma fachada para avaliação da universidade?

- Fachada como representação coletiva: o ator se vê em um papel social em que geralmente verifica que uma determinada fachada já foi estabelecida coletivamente para esse papel. Em cada país e no conjunto das universidades, estariam se formando representações coletivas sobre avaliação? 
- Aparência e maneira: são estímulos para revelar o status social do ator; podem constituir um aparato ritual temporário do indivíduo. $\bigcirc$ ator usa a "maneira" pela qual os estímulos funcionam para informar sobre o papel de interação que espera desempenhar na situação que se aproxima. Que papéis de interação os estudantes estariam desempenhando nas situações de avaliação das universidades?

Goffman afirma que o indivíduo age como ator, mostrando sua fachada, e como personagem. Seus estudos, que dizem respeito à sociedade anglo-americana, podem ser transferidos para o nosso meio na medida em que "dão abrigo ao funcionamento do eu individual" que se representa para outros indivíduos: "O ator é um atormentado fabricante de impressões envolvido na tarefa demasiado humana de encenar a representação. O personagem é algo alojado no corpo do possuidor, um nódulo da psicologia da personalidade" (1989, p.231).

Desse ponto de vista, os sujeitos, como personagens, representam a cena geral, produto dos acontecimentos locais; os sujeitos, como atores, desenvolvem a capacidade de aprender, especialmente quando treinados para desempenhar um papel, o caso dos estudantes na universidade, por exemplo. Avaliados por seus professores, eles passam a desempenhar o papel de fabricantes de impressões, sujeitos avaliadores de suas universidades.

\section{METODOLOGIA}

Para conhecer as representações dos estudantes sobre a avaliação, mudanças e melhorias decorrentes desta, os questionários aplicados aos alunos universitários continham três questões abertas, sendo a última desdobrada em quatro alternativas. A primeira pergunta era sobre suas opiniões a respeito da avaliação das universidades, propositadamente sem identificar o formato da avaliação (auto-análise, exame nacional, avaliação interna, externa, da aprendizagem ou educacional). A segunda questão dizia respeito à vinculação da avaliação com possíveis melhoras observadas em seu curso de origem; a terceira perguntava se os resultados da avaliação provocaram mudanças e, em caso positivo, quais as evidências das mudanças no ensino, pesquisa, extensão ou cooperação com a sociedade. As universidades, quando da aplicação dos questionários apresentavam o perfil identificado no quadro I. 
QUADRO I

PERFIL DAS UNIVERSIDADES PARTICIPANTES

\begin{tabular}{|l|c|c|c|}
\hline & UFRGS & UFPel & UA \\
\hline Ano-base & $2001 / 2$ & $2001 / 2$ & $2002 / 1$ \\
\hline Alunos & 18.071 & 10.169 & 10.454 \\
Docentes & 2.435 & 917 & 885 \\
Pessoal Téc.-Adm. & $2.940(1999)$ & 1.156 & 507 \\
Departamentos & 96 & 50 & 15 \\
\hline
\end{tabular}

Fonte: Censo de Educação Superior: sinopse 1995-2002 - Inep (disponível em: www.ufrgs.br; mww.ufpel.tche.br; www.ua.pt; acesso em: maio 2004).

Na UFRGS, o material de pesquisa foi encaminhado com o material individual de matrícula e também por e-mail no semestre 200 I/2002. Na UFPel, o material de investigação foi encaminhado no momento das matrículas. Em alguns cursos houve dificuldades nos atos de entrega aos alunos e posterior devolução. Na Universidade de Aveiro, tendo em vista as datas aprazadas no projeto, o questionário foi aplicado de forma intencional a turmas de alunos de disciplinas oferecidas a estudantes de diferentes cursos no semestre (200 I/ 2002) correspondente ao $2^{\circ}$ semestre brasileiro (200 I/2002).

Responderam ao questionário, 346 alunos das universidades brasileiras (22\% da UFRGS e 78\% da UFPel), e I 30 alunos da universidade portuguesa, totalizando 476 alunos.

\section{ANÁLISE DAS RESPOSTAS}

Depois de coletados, os dados foram sistematizados com auxílio do software Qualitative Solutions and Research for Non-numerical Unstructure Data*Indexing Searching and Theorizing - QSR NUD*IST -, que trabalha os dados sob orientação de princípios de codificação. Esses são armazenados num sistema de nós, indexados em forma de árvore. Os questionários receberam numeração, e cada resposta foi armazenada em unidade de texto - UT. Cada unidade de texto trazia no seu cabeçalho informações que permitiam a sua "identificação": por universidade e curso do estudante, com numeração seqüencial, possibilitando a busca de outras respostas do mesmo questionário.

As respostas foram lidas inúmeras vezes pelos membros do grupo de pesquisa para dar início à construção das primeiras categorias explicativas. Para 
criar o sistema de categorização utilizamos algumas das ferramentas disponibilizadas pelo software QSR NUD*IST, que facilitaram, por exemplo, a verificação da recorrência de palavras-chave em cada questionário e na subcategorização.

Para entender o sentido das palavras dos estudantes a equipe de investigação realizou uma leitura grand tour das respostas aos questionários. $\bigcirc$ entendimento dos significados foi trabalhado pelos membros do grupo, individualmente, e depois foi feita uma triangulação nas sessões de estudo do grupo de pesquisa. Conferidas as concordâncias e as discrepâncias, passou-se a uma nova rodada de análises, sempre que aparecia uma discordância ou uma dúvida entre os pesquisadores sobre o sentido da manifestação do estudante. $\bigcirc$ grupo debruçou-se sobre 2.206 respostas posteriormente desdobradas em 3.610 UTs, dispostas em forma de relatórios NUD*IST, obtendo-se um grande número de posições a respeito da avaliação institucional e da aprendizagem. Vários meses foram empregados nesse processo, tendo em vista o número total de respostas'. Observa-se que uma mesma resposta poderia ser desdobrada em mais de uma UT.

A vantagem do uso dessa ferramenta sobre outras formas de análise qualitativa de textos e de conteúdos reporta-se ao fato de que ela sistematiza e hierarquiza as unidades. De certa maneira limita o viés, comum em estudos dessa natureza, de o pesquisador citar uma fala de um respondente que confirme aquilo que ele quer provar e não mostre ao leitor outras possibilidades. O NUD*IST "varre" todos os textos. Dificulta inferências ou relativismos.

\section{RESULTADOS: O QUE OS ESTUDANTES DIZEM SOBRE AVALIAÇÃO}

As respostas dos alunos sobre a avaliação institucional, mudanças e melhoras atribuídas, permitem inferir que, em conjunto, os estudantes das três universidades reconhecem a importância dos processos de avaliação e formam seus próprios conceitos sobre avaliação institucional e sobre avaliação educacional ou da aprendizagem.

I. Parte do processo de análise originou o estudo "Students'representations on the influence of institutional evaluation on teaching improvement", apresentado no Seminário Internacional Teaching and Learning in Higher Education. New trends and innovations (University of Aveiro, |3- I7 april, 2003). 
QUADRO 2

RESPOSTAS VÁLIDAS POR QUESTÃO EM CADA UNIVERSIDADE

\begin{tabular}{|l|c|c|c|c|}
\hline & UA & UFPel & UFRGS & $\Sigma$ \\
\hline Questão 1 & 127 & 265 & 76 & 468 \\
Questão 2 & 126 & 266 & 74 & 466 \\
Questão 3.1 & 109 & 260 & 69 & 438 \\
Questão 3.2 & 92 & 241 & 52 & 385 \\
Questão 3.3 & 101 & 236 & 55 & 392 \\
Questão 3.4 & 32 & 13 & 12 & 057 \\
\hline$\Sigma$ & 587 & 1281 & 338 & 2.206 \\
\hline
\end{tabular}

Fonte: Questionário alunos (29/1/2004).

Em relação à primeira questão da pesquisa, foram destacadas na análise, duas grandes categorias, ou nós, avaliação institucional e avaliação educacional ou da aprendizagem. A primeira foi entendida por meio de subcategorias explicativas "legitimidade da avaliação", "avaliação como responsabilidade social", "avaliação processual", "avaliação construtiva", "avaliação como regulação ou controle pelo Estado ou pelo mercado", com base em aspectos positivos e negativos desse controle.

As subcategorias (UTs), individualmente ou no conjunto, passavam a constituir articuladores de entendimentos para os sentidos de cada nó ou categoria principal. Assim, entendemos que a avaliação institucional é vista como legítima pelos estudantes quando ela diz respeito à formação de um padrão de qualidade para o ensino ou quando ela caracteriza discrepâncias ou diferenças entre instituições ou, ainda, quando ela é sensível e consegue detectar a diversidade e os desempenhos diferentes, ou seja, não comparáveis. Em um outro nó de entendimento, na avaliação como processo, os respondentes percebem que nem todos conhecem esse processo, tanto os estudantes quanto a sociedade, mas formam um conceito de avaliação como um todo, cujos resultados devem ser aplicados na promoção de melhorias. Ao representar a avaliação institucional como uma forma de controle, positiva, os estudantes se referem ao Exame Nacional de Cursos, aplicado no Brasil, o Provão, e à universidade que se adapta às demandas do mercado. Nessa perspectiva, reportam-se a uma imagem positiva das instituições, que perpassa os conceitos (notas e classificações) provindos dos exames nacionais, os quais também contribuem para uma 
forma de comparação (saudável) entre cursos e universidades. Ao representar a avaliação institucional como uma forma de controle, com aspectos negativos, os estudantes referem que o Provão rotula para comparar.

\section{AVALIAÇÃO INSTITUCIONAL}

Ao especificar cada nó de entendimento das representações sobre avaliação institucional observa-se que os estudantes consideram que a avaliação tem legitimidade porque faz o acompanhamento de qualidade. Muitas vezes, os estudantes reconhecem que o modo de fazer avaliação não é legítimo. Os critérios para uma avaliação legítima deveriam considerar a produção do conhecimento, a sua divulgação e a eficácia das instituições. Os resultados das avaliações legítimas deveriam ser amplamente divulgados e aplicados e a avaliação seria boa para conhecer e manter o padrão de qualidade do ensino e melhorar o posicionamento da instituição com obtenção de boas notas. A qualidade dos cursos, dos docentes, da infra-estrutura e da universidade como um todo, serve para aprimorá-la e favorece um retorno para a coletividade.

A avaliação institucional é representada como uma forma de diagnóstico da qualidade do ensino, para que todos saibam as reais condições das universidades; para identificar suas falhas, pontos fortes e fracos. A avaliação formal deixa a desejar no que se refere à ação, porque não produz efeitos práticos. A avaliação está associada com discrepância, ou seja, o conhecimento das diferenças - em que níveis estão as universidades e o ensino - isto seria obtido mediante comparação. Serve para saber o que está bem ou mal na universidade. A avaliação, então, se prestaria a destacar a diversidade e aqueles desempenhos que não são comparáveis. Por isso, a avaliação não deve ser a mesma para todos. Deve atender a diferentes modelos de universidade e estabelecer critérios para diferentes universidades. Não deve ser a mesma para todos os cursos, deve haver critérios para atender especificidades regionais.

Ao expressar o entendimento da avaliação como responsabilidade social, os estudantes representam uma universidade que procura adequar-se às necessidades da sociedade ou melhorar a formação de funcionários e professores. Para eles, a avaliação permite verificar se há integração da universidade com a sociedade, ou seja, se ela está ou não interagindo com base nas demandas da sociedade. 
TABELA I

AVALIAÇÃO DA UNIVERSIDADE

\begin{tabular}{|c|c|c|c|c|c|}
\hline \multirow{3}{*}{ Categoria para avaliação da universidade [ I ] } & \multicolumn{3}{|c|}{ Brasil } & \multirow{3}{*}{$\frac{\text { Portugal }}{\text { UA }}$} & \multirow[t]{3}{*}{ Total } \\
\hline & UFRGS & UFPEL & UFRGS & & \\
\hline & \multicolumn{3}{|r|}{ UFPel } & & \\
\hline Totais referem-se a unidades de texto & $\%($ (I20UT) & $\%(334 \mathrm{UT})$ & $\%(454 \mathrm{UT})$ & $\%(145 U T)$ & $\%(599 U T)$ \\
\hline \multicolumn{6}{|l|}{ I. Avaliação institucional } \\
\hline ।. I. Legitimidade da avaliação & 28,3 & 27,8 & $28,0(1)$ & $20(2)$ & $26,0(1)$ \\
\hline ।. I.।. Padrão de qualidade do ensino & 9,2 & 5,1 & 6,2 & 4,8 & 5,8 \\
\hline I.1.2. Diagnóstico/Discrepância & 7,5 & 10,8 & 9,9 & $14,5(3)$ & II \\
\hline I. I.3. Diversidade e desempenhos não comparáveis & 2,5 & 2,1 & 2,2 & 0 & ।,7 \\
\hline I.2. Avaliação como responsabilidade social & 7,5 & 2,7 & 4 & 2,1 & 3,5 \\
\hline 1.3. Processo de avaliação & 0 & 0,3 & 0,2 & 0 & 0,2 \\
\hline \multicolumn{6}{|l|}{ |.3. I. Deve haver avaliação da universidade } \\
\hline como um todo & 5 & 1,5 & 2,4 & 5,5 & 3,2 \\
\hline \multicolumn{6}{|l|}{ I.3.2. Formatos avaliativos são pouco conhecidos } \\
\hline pelos alunos & 0 & 4,5 & 3,3 & 4,8 & 3,7 \\
\hline \multicolumn{6}{|l|}{ I.3.3. Formatos avaliativos são pouco conhecidos } \\
\hline pela sociedade & 0 & 0 & 0 & 0,7 & 0,2 \\
\hline I.3.4. Resultados divulgados & ।,7 & 0,3 & 0,7 & 1,4 & 0,8 \\
\hline \multicolumn{6}{|l|}{ I.3.5. Resultados da avaliação devem ser aplicados } \\
\hline na promoção de melhorias & 2,5 & 0 & 0,7 & 2,1 & । \\
\hline 1.4. Avaliação construtiva & 3,3 & 0,9 & ।,5 & 7,6 & 3 \\
\hline \multicolumn{6}{|l|}{ I.5. Avaliação como forma de controle/regulação } \\
\hline \multicolumn{6}{|l|}{ do Estado e mercado* } \\
\hline \multicolumn{6}{|l|}{ 1.5. I. Aspectos negativos } \\
\hline 1.5. I.I. Exames nacionais & 18,3 & 20,1 & $19,6(2)$ & 0 & $14,9(2)$ \\
\hline 1.5. I.2. Avaliação que rotula para comparar & 0,8 & 2,4 & 2 & 0 & 1,5 \\
\hline \multicolumn{6}{|l|}{ 1.5.2. Aspectos positivos } \\
\hline I.5.2. I. Exames nacionais & 5,8 & 3,3 & 4 & 0 & 3 \\
\hline 1.5.2.2. Universidade e adequação ao mercado & 2,5 & 3,6 & 3,3 & 2,8 & 3,2 \\
\hline I.5.2.3. Imagem positiva da universidade & 0 & 0,3 & 0,2 & 9 & 2,3 \\
\hline 1.5.2.4. Avaliar para comparar & 0 & 0 & 0 & 2,1 & 0,5 \\
\hline 2. Avaliação educacional & 5 & 14,4 & $11,9(3)$ & $22,8(1)$ & $14,5(3)$ \\
\hline
\end{tabular}

Fonte: Questionário alunos QSR NUD*IST unidades de texto (29/I/2004).

* A análise captou e codificou aspectos positivos e negativos do item I.5 (ver descrição no texto). 
Alguns estudantes entendem a avaliação como um processo que deveria promover maior aproximação e harmonia entre a instituição, o aluno e a sociedade, e para tanto precisaria considerar a universidade como um todo. Mas os formatos avaliativos são pouco conhecidos pelos alunos e pela sociedade, segundo a opinião dos respondentes. Em oposição a uma avaliação punitiva, deveria haver uma avaliação construtiva, que constituísse um processo constante e contribuísse para mudanças positivas. Avaliar como um todo, dizem os estudantes, se faz no geral, mas a melhoria tem que ser em cada curso, especificamente, ou seja, deve-se fazer avaliação do global e da parte em interação. Se os alunos são avaliados com provas e conceitos, no mesmo sentido a sociedade pode avaliar a universidade quanto à qualidade do ensino e dos serviços prestados. A avaliação é construtiva porque serve para o crescimento das universidades, vem para melhorar, para mudar, para avaliar a todos.

A avaliação também é vista e entendida como uma forma de controle ou regulação do Estado e do mercado em seus aspectos negativos. Nesse caso, confunde-se, entre os estudantes brasileiros, com os exames nacionais, o Provão, que são caracterizados como uma avaliação vertical, de cima para baixo, que faz ranqueamento entre universidades. Não vem para melhorar, mas para excluir as universidades públicas das verbas destinadas à educação. O governo que adota essa forma de avaliação é visto como gerenciador. O Provão, ou avaliação do Ministério da Educação, seria insuficiente para avaliar as instituições e estaria voltado para a privatização das universidades. Além disso, é uma avaliação que rotula para comparar, uma avaliação classificatória que pode, segundo os estudantes, prejudicar o futuro profissional, por se tratar de um processo que gera competição, contrapondo as IES dentro de parâmetros de qualidade.

Os exames nacionais (Provão/BR) são, no entanto, representados de forma positiva por outros estudantes, que os vêem como uma grande arma para a melhoria do ensino. Alguns pensam que deve ser fiscalizado o uso dessa avaliação na contratação do profissional, porque ela faz o controle da situação das universidades quanto à estrutura e qualidade de ensino. Para eles, a punição seria vantajosa para o governo, e esse formato de avaliação seria necessário porque identificaria universidades que não possuem estrutura para formar bons profissionais. Desse modo, o Provão, ou avaliação do MEC, é importante. 
Um dos efeitos da avaliação seria a adequação da universidades às demandas do mercado e das novas tecnologias. As universidades devem atender ao mercado. A avaliação gera uma imagem positiva da universidade porque os resultados são publicados e a sociedade precisa conhecê-los. As pessoas são informadas sobre a universidade e isso traz credibilidade e legitimidade aos cursos, bem como segurança sobre a qualidade que está sendo aferida. Ou seja, avaliar serve para comparar, e é importante estabelecer qualidade na comparação entre as IES, pois o fomento da competitividade gera melhorias.

\section{AVALIAÇÃO EDUCACIONAL E DA APRENDIZAGEM}

A categoria da avaliação educacional mostra a compreensão dos estudantes sobre a avaliação da aprendizagem na universidade (Tab. I). Para eles, sob o aspecto positivo, a avaliação, como tem sido feita, cria maior mobilidade para o professor entre as especificidades de cada curso, de cada aluno. Em geral todos os docentes seguem mais ou menos um padrão. As notas dos alunos nas provas refletem bem o conhecimento destes, portanto, esse é um método muito eficaz para medir o conhecimento dos alunos.

Sob o ponto de vista de outros alunos, a avaliação apresenta aspectos negativos. A avaliação feita por meio de provas é inadequada. Os parâmetros subjetivos dão margem a injustiças. Cada professor avalia como deseja. Os conteúdos não são pensados de uma forma prática, eles deveriam propor e promover maior interação da universidade com a sociedade na qual estão inseridos. As provas não dão conta das especificidades de cada caso, de cada aluno. Existem formas mais sensatas para avaliar o ensino de uma universidade. Esta forma de avaliação prima pela quantidade e não pela qualidade do ensino, pois não é uma avaliação contínua que visa verificar todo o desenvolvimento do aluno durante o semestre. Às vezes a forma de avaliação faz com que o aluno se sinta pressionado.

Especificamente em Portugal, os estudantes dizem que a avaliação do aluno deve ser contínua e não somente no exame final; deveria ser feita por meio de trabalhos complementares ou então de freqüências práticas ao longo do semestre.

Outros alunos dizem que a avaliação talvez possa provocar mudanças. A universidade pode se envolver mais com a sociedade, e deveria fazê-lo, 
desenvolvendo ações mais cooperativas para o benefício de ambas as partes. Poderá haver mudanças nos projetos de extensão se o governo investir mais na universidade. Na relação entre universidade e sociedade os alunos incluem uma "imagem da universidade" que aumentará a credibilidade dela e dos profissionais por ela formados, se a instituição obtiver um conceito elevado. A avaliação será, no entanto, prejudicial à universidade se o conceito atingido for baixo, pois seus cursos não terão procura e seus formandos terão dificuldade de se encaixar no mercado de trabalho. Ou seja, a avaliação determinará o modo pelo qual a sociedade irá aceitar a universidade e seus profissionais, que poderá ser positivo ou negativo, dependendo dos conceitos obtidos.

\section{ANÁLISES COMPARATIVAS DE RESPOSTAS E DE CONTEXTOS DA AVALIAÇÃO}

Analisando os dados sobre melhorias pós-avaliação, referentes às universidades brasileiras, observa-se que emergem dois nós que caracterizam uma polarização: $12,3 \%$ das respostas (UTs) confirmam que a avaliação "produz melhorias" na universidade e I 1,7\% das UTs são negativas, ou seja, afirmam que a avaliação "não produz melhorias" na universidade. No caso afirmativo destaca-se a função diagnóstica da avaliação. Ao conhecer os problemas podem-se encontrar suas soluções. Dentre as respostas positivas, os estudantes fixam a melhoria do ensino e da qualidade dos cursos, o fato de a avaliação funcionar como um mecanismo de pressão para que os professores repensem suas práticas pedagógicas. Quando negam as melhorias, os estudantes falam que a avaliação e suas metodologias são inadequadas. Culpam a gestão da universidade por sua inércia e falta de responsabilidade em relação aos processos de conhecimento produzidos pelas avaliações. Para alguns, não são observadas melhorias em seus cursos. Elas existiriam "só" em teoria.

$\mathrm{Na}$ Universidade de Aveiro, em Portugal, os estudantes tendem a formar uma imagem afirmativa sobre as melhorias trazidas pela avaliação. Para esse grupo, com um contingente ligeiramente maior de respostas (UTs), a avaliação efetivamente produz melhorias ( $14,4 \%$ UTs), ou, conforme indicado, talvez possa produzir melhorias ( $10,3 \%$ UTs). Em caso positivo, porque oferece uma imagem da universidade, um reconhecimento e, com isso, permite maior inserção do estudante no mercado de trabalho. Os estudantes destacam a 
avaliação como uma forma de diagnóstico para melhorar. Reconhecem melhorias no ensino e na qualidade dos cursos. Dizem que se houver atitude para mudar, se forem corrigidas as falhas, se forem envolvidos todos os membros da comunidade, a avaliação talvez possa produzir melhorias.

que isto quer dizer? No caso brasileiro, a crítica negativa foi predominante entre os estudantes da UFPel, que mostraram suas dúvidas sobre os efeitos positivos da avaliação. Eles não estavam vendo as melhorias e se queixavam dos gestores da universidade. Vale repetir suas observações. Durante os anos em que estão na universidade eles apenas ouvem reclamações sobre a qualidade dos laboratórios, bibliotecas e recursos para aulas. Para eles, a classificação (ranking) das universidades não resolve os problemas internos das IES públicas. Parece-lhes que as universidades estão mais preocupadas com seu conceito (no Provão) do que com as melhorias em cada curso. Por isso eles falam que as metodologias não coincidem com a realidade, com a verdadeira situação da universidade brasileira. Com esse formato de avaliação as universidades têm de se adaptar às normas e estas não levam em conta a falta de recursos. Como refere um aluno: "Até hoje, depois de vários questionamentos com meus colegas, chegamos às mesmas conclusões: mais uma restrição (Provão) para acobertarmos as nossas limitações" (UFPel-Física, 437-437). Os estudantes afirmam que se a avaliação fosse construtiva, com outro formato, a degradação da imagem da universidade pública, seus problemas se tornariam públicos para uma solução e não mais seriam "um motivo de vergonha para a universidade pública". Nesse caso, estudantes de alguns cursos dizem que houve melhorias apenas na época de visitas dos avaliadores do Ministério da Educação, principalmente nas salas de aulas onde se colocaram cortinas ou maior número de computadores. Outros estudantes, de outros cursos, valorizam as melhorias na estrutura física. Acham que a avaliação mobiliza os reitores, departamentos e colegiados.

O discurso dos estudantes brasileiros aparenta um toque de pessimismo sobre a avaliação por meio de exames nacionais, que não mobiliza para as reais melhorias necessárias - as internas, dos cursos, de sua infra-estrutura. Parecem repetir as críticas mais ou menos constantes sobre o Provão que se disseminaram nos últimos anos. Estando dentro da universidade, eles se consideram "testemunhas oculares" do que acontece, do que a avaliação em forma de prova não consegue mostrar, ou seja, um comportamento de "facha- 
TABELA 2

AVALIAÇÃO E MELHORIAS NA UNIVERSIDADE

\begin{tabular}{|c|c|c|}
\hline \multirow{2}{*}{ Categoria para avaliação e melhorias na Universidade [ 2 ] } & Brasil & Portugal \\
\hline & UFRGS+UFPEL & UA \\
\hline Totais referem-se a unidades de texto & $\%(504$ UT) & $\%(194 \cup T)$ \\
\hline I. Avaliação produz melhorias & $12,3(1)$ & $14,4(1)$ \\
\hline \multicolumn{3}{|l|}{ I.I. Imagem } \\
\hline I.।.।. Somente imagem externa & । & 0,5 \\
\hline I.I.2. Reconhecimento & । & 7,7 \\
\hline 1.2. Avaliação do docente pelo aluno & 0,6 & 1,5 \\
\hline |.3. Inserção no mercado de trabalho & । & 6,7 \\
\hline 1.4. Diagnóstico para melhorar & 5,6 & $8,2(3)$ \\
\hline 1.5. Melhoria do ensino/qualidade/cursos & 4,6 & 6,7 \\
\hline I.6. Funciona como mecanismo de pressão & 3,2 & 1,5 \\
\hline 1.7. Repensar as práticas pedagógicas do professor & 2 & 3,6 \\
\hline I.8. Desempenho dos alunos-exigência do professor & 2,8 & 2,6 \\
\hline 1.9. Alterações curriculares & 0,6 & 2,6 \\
\hline I. I0. Melhoras somente em época de avaliação & । & 0 \\
\hline \multicolumn{3}{|l|}{ ।. I।. Participação - dos alunos, docentes, funcionários e/ou } \\
\hline egressos no processo & । & 0,5 \\
\hline \multicolumn{3}{|l|}{ 1.12. Outras } \\
\hline 2. Avaliação não produz melhorias & ||$, 7(2)$ & 2,6 \\
\hline 2.1. Nem todos os cursos são avaliados & 2 & 0 \\
\hline 2.2. Avaliação inadequada/ausência de metodologias adequadas & 5,2 & 4,1 \\
\hline 2.3. Melhorias só em teoria & 1,4 & 0 \\
\hline 2.4. Falta de investimentos e de infra-estrutura & 4 & 0 \\
\hline 2.5. As melhorias não são conseqüência da avaliação & 3,6 & । \\
\hline 2.6. Gestão burocrática inerte e sem responsabilidade & 2,8 & 0 \\
\hline 2.7. Não há fluxo de informação-não é divulgado & 3 & 0 \\
\hline 2.8. Não há melhoria interna/cursos & $7,7(3)$ & । \\
\hline \multicolumn{3}{|l|}{ 2.9. Outras } \\
\hline 3. Avaliação talvez possa produzir melhorias & 5,6 & $10,3(2)$ \\
\hline 3.1. Espera-se que sim & 2,2 & 2,1 \\
\hline 3.2. Legitimação da avaliação - utilização dos dados & 2 & 2,1 \\
\hline 3.3. Se for assumida pelos decisores & 0,6 & । \\
\hline
\end{tabular}




\begin{tabular}{lcc} 
(continuação) & & \\
\hline Categoria para avaliação e melhorias na Universidade [ 2 ] & Brasil & Portugal \\
\cline { 2 - 3 } & UFRGS+UFPEL & UA \\
\hline Totais referem-se a unidades de texto & \% (504 UT) & $\%($ I 94 UT $)$ \\
\hline 3.4. Melhoria apenas em alguns cursos & 1 & 0 \\
3.5. A longo prazo & 0,6 & 0,5 \\
3.6. Envolvendo todos os membros da comunidade & 1 & 4,1 \\
3.7. Se houver participação & 1 & 1 \\
3.8. Diagnóstico bem-feito & 1,4 & 3,6 \\
3.9. Se houver atitude para mudar/se corrigirem as falhas & 1,4 & 5,2 \\
3. I0. Outras & & 0,5 \\
4. Não soube responder/ não tinha opinião a respeito & 2,8 & 2,1 \\
5. Outras & 1,8 & 0 \\
6. Respostas não válidas & 0,2 & 2,1 \\
7. Não respondidas & 0,8 &
\end{tabular}

Fonte: Questionário alunos QSR NUD*IST unidades de texto ( 29/I/2004).

da", como mostra Goffman (1989). Para eles, as limitações da universidade pública deveriam ser mostradas ao público, denunciadas, o que, de certa forma, tentaram fazer ao responder aos questionários da pesquisa.

Em Portugal, os alunos referem melhorias associadas à imagem da universidade: o curso fica mais conhecido, a universidade com boa reputação, com mais prestígio perante as faculdades "mais carismáticas do país". Isso ajuda para conseguir emprego. Se os cursos melhoram, os licenciados são "mais bem enquadrados" no mercado de trabalho.

O discurso dos respondentes da universidade portuguesa parece considerar positivo o ranqueamento das universidades feito pelos jornais. No país não existe um exame nacional de final de curso, a avaliação institucional é realizada pela Comissão Nacional de Avaliação da Educação Superior - CNAVES -, e acompanhada pelo Conselho de Reitores das Universidades Portuguesas - Crup. Contudo, os jornais fazem suas classificações (ranking) a partir dos resultados das avaliações. Na pesquisa, o Ministério de Ciência e Educação Superior nomeia os centros de excelência do país. A competição parece ser uma das chamas que valoriza o processo de avaliação e induz a melhorias da universidade, na percepção dos estudantes. Coloca a universidade nova em disputa com as mais tradicionais do país. Isso favorece a acolhida dos profissionais egressos no merca- 
do de trabalho, talvez, um mercado concorrido. Como afirmam Santiago et al. (2003, p. I 0), as universidades portuguesas estão vivendo um momento de práticas "managerialistas" em que ocorre uma pressão, "...uma representação fantasmagórica das receitas mágicas da qualidade, excelência, competição". Talvez esse discurso, até certo ponto darwinista, como alertam os autores, esteja sendo assimilado nas representações dos estudantes.

Em relação a mudanças específicas no ensino, na pesquisa e na extensão, observam-se diferenças entre os respondentes dos dois países. Em geral, no Brasil, os estudantes apontam, em $5 / 3$ UTs analisadas, a não existência de mudanças, ou a falta de evidência de que isso ocorra após avaliação, ou ainda que os resultados não são claros, no ensino ( $12,1 \%)$, na pesquisa $(10,9 \%)$ e na extensão (1 I,3\%). Dentre as respostas dos estudantes brasileiros, apenas 3,3\% confirmam a existência de mudanças no ensino como resultado da avaliação.

Há respostas positivas para a categoria ensino quando os estudantes brasileiros se referem ao professor - reconhecem que aumentou sua qualidade e seu esforço após a avaliação ( 1 1,9\%). Nesse caso, isso parece acontecer quando e porque ocorre uma avaliação externa das condições de ensino de um curso determinado; ou porque os professores também são avaliados mediante a gratificação de estímulo à docência - GED -, sistema merit pay implantado pelo MEC. Essa avaliação vincula ganhos salariais anuais à pontuação e qualificação docente. Os estudantes podem estar se referindo a um fato visível na qualidade da formação docente - nas universidades públicas brasileiras houve acentuado acréscimo de docentes pós-graduados e doutorados na última década.

Em Portugal, a maior incidência de respostas diz respeito à existência de mudanças após avaliação, com destaque para a eficiência do ensino (10,7\%). São apontadas, ainda de forma positiva, as mudanças no currículo, nas práticas de ensino e no aumento do esforço do professor.

Sobre a pesquisa, na mesma proporção de respostas, os estudantes brasileiros negam (10,9\%) e afirmam (10,2\%) que ela muda com a avaliação. Quando afirmam, apontam o aumento do número de pesquisas, mais incentivo e aumento de investimentos, qualificação de professores e de alunos como as mudanças percebidas. Ainda, com relação à pesquisa, os estudantes portugueses concordam que a avaliação da universidade provoca mudanças. "Resultados positivos na avaliação provocam mais e melhor investigação" (9,7\%); há mais incentivos se é feito um diagnóstico. 
Algumas nuanças chamam a atenção: 4,9\% em um total de 384 respostas dos estudantes brasileiros, e 4,5\% dos estudantes portugueses em um total de 134 respostas afirmam que a "área da pesquisa não interessa aos estudantes de licenciatura".

Há respostas positivas dos estudantes brasileiros, quando apontam mudanças na extensão, relação da universidade com a sociedade $(7,1 \%)$ e maior integração e cooperação com a sociedade. Um grupo de estudantes refere a não existência de mudanças nesta relação ( I 1,3\%), mas confirma alguma mudança quanto a projetos de extensão, reconhece que aumentou o número deles. Os alunos portugueses apontam mudanças na extensão no que diz respeito à sociedade, afirmando haver "maior integração e cooperação" (I 4\%), com melhor inserção dos alunos no mercado de trabalho (9,6\%). Se a avaliação provocar mudanças, os respondentes acreditam que isso vai determinar a aceitação da universidade e do profissional formado por ela (5,7\%). A Universidade de Aveiro destaca-se por sua inserção no mercado de trabalho localregional, tendo sido fundada com esse pressuposto ${ }^{2}$. A função de extensão parece ser entendida pelos alunos como relação com a sociedade mediante potencialização dos mercados de trabalho.

\section{Opiniões dos alunos sobre outras mudanças e conclusões}

Foi um dos objetivos deste estudo contribuir para o processo de gestão das universidades. Assim, interessa mostrar que os estudantes afirmam que as avaliações servem para resolver questões mais gerais, tais como esclarecer qual é a missão da universidade ou pautar decisões. Como síntese e para concluir, destacamos outras afirmações que dizem respeito ao processo de gestão das universidades.

2. O curso de graduação em Vidro e Cerâmica, por exemplo, foi criado para atender à tradição local milenar no fabrico de porcelanas, azulejos e vidros. Na região situam-se fábricas destes materiais, dentre elas, a conhecida Fábrica de Porcelanas Vista Alegre a qual, no passado, produzia a louça que ornava as mesas da aristocracia européia. Hoje produz a louça que é usada por uma parcela da população mundial. Em seu processo de expansão a empresa comprou a Fábrica de Porcelanas Renner do Brasil, no entanto, à época da pesquisa, o curso de graduação em Vidro e Cerâmica tinha reduzida procura de alunos. 
No discurso dos estudantes portugueses, destacamos a sua preocupação com a relação universidade-empresa que inclui a otimização de estágios de final de curso e a avaliação dos serviços prestados ao setor privado pela universidade. Eles reafirmam que a avaliação melhora o nível de qualidade e a formação dos alunos, mudando suas mentalidades. Os estudantes brasileiros deram poucas respostas a essa questão; alguns disseram que desconheciam o tema. Quando houve resposta, elas não apontaram outras mudanças, sugestões ou expectativas, mas mantiveram críticas à política de sucateamento das universidades públicas brasileiras e reafirmaram que o Provão não é a melhor forma de avaliar as universidades.

No âmbito geral, realçamos as expectativas dos estudantes sobre o valor intrínseco da avaliação institucional, reafirmado, tanto pelos brasileiros quanto pelos portugueses. Para todos eles a avaliação das universidades tem legitimidade, é uma responsabilidade social, pois promove as condições ideais para que aconteçam melhorias. Preferencialmente a avaliação deveria ser construtiva e processual. Os estudantes a vêem como forma de controle e regulação pelo Estado e pelo mercado, apresentando aspectos positivos e negativos.

Lembramos que este estudo realizou-se em dois "palcos", montados em países considerados como o sul do norte - Portugal - e o norte do sul - Brasil. Em ambos os países, os processos de avaliação das universidades estavam em evidência. Neles se formaram as representações dos atores estudantes, foram mostradas suas fachadas pessoal e coletiva, aparências e maneiras de ver as situações. Neles foram desenroladas as encenações de atores que circulam cotidianamente nos espaços micro políticos das universidades públicas. Nesses "palcos" situamos as construções representacionais e simbólicas dos atores a propósito de suas ações e dos contextos em que elas se desenvolvem. Compreendemos que esses "palcos" foram estruturantes para as opiniões expressadas. Como não há gestão da universidade sem conflito e negociação, pensamos que a análise dessas construções pode constituir um elemento importante da avaliação institucional e de gestão, capaz de colaborar para pactuação de melhorias e mudanças na universidade (Santiago et al., 2004).

Este estudo, na forma em que foi organizado, inseriu-se na "estrutura dos encontros sociais". Como ressalta Goffman, trata-se de fenômeno que ocorre entre pessoas que vivem em interação ou na presença física imediata umas das outras. Para os estudantes transindivíduos que vivem dentro da estrutura de uma 
instituição forte como a universidade pública, impõe-se manter "uma única definição da situação, definição que tem de ser expressa, e esta expressão mantida em face de uma grande quantidade de possíveis rupturas" (1989, p. 233).

Como visto, o discurso sobre avaliação nos dois países estendeu-se entre um pólo positivo e um negativo, por vezes assumiu uma configuração híbrida, comtemplada nas respostas do "talvez". Esse fato mostra que as opiniões dos alunos dos dois países não caracterizaram uma reprodução simples de outros discursos, externos à universidade. Os alunos não se limitaram a fazer eco ao que se passava nos comentários dos jornais ou da televisão, ou das discussões no interior dos grupos acadêmicos. Os estudantes mostraram capacidade de argüir, fazer crítica de forma original. Nos dois países, a autonomia das universidades, bem como sua responsabilidade em relação ao mercado de trabalho, foi destacada. Ou seja, as respostas dos estudantes, seus valores e crenças ressaltaram tanto a estrutura "englobante" (palavras suas) da cultura da avaliação no sistema educativo dos países quanto a estrutura "englobada" da avaliação na realidade cotidiana das universidades.

São muitas as influências que os estudantes recebem ao estar na universidade. As culturas estudantis de repúdio à avaliação única de uma prova nacional, no caso brasileiro, parecem ter influenciado suas percepções sobre os formatos avaliativos. As culturas estudantis relativas à competitividade do mercado, no caso português, valorizaram a avaliação institucional como regulação. No entanto, criticaram a avaliação da aprendizagem reguladora e expressa apenas em formato de única prova realizada em sala de aula e ao final do semestre. Isso porque, não devemos esquecer que, sendo inúmeras as influências, os estudantes precisam limitar suas definições, mas o fazem com base nas interações que as originam.

Os indivíduos que realizam uma interação frente a frente num palco de teatro devem satisfazer a exigência fundamental das situações reais. Devem expressivamente manter uma definição de situação: mas fazem isto em circunstâncias que Ihes facilitaram criar uma terminologia adequada às tarefas de interação das quais todos nós compartilhamos. (Goffman, 1989, p.233)

Os depoimentos dos alunos, personagens-atores fundamentais dos processos de avaliação da e na universidade implicaram reflexões sobre o melhor 
e o pior da avaliação. Houve coerência nos discursos ainda que os países sejam diferentes, que os "palcos" estejam distantes e os estudantes tenham sido submetidos a dispositivos micro e macroinstitucionais, diferenciados de avaliação. De certo modo, os processos de avaliação produziram uma forma de aprendizagem estudantil com partilha de significados, com percepção sobre o funcionamento institucional, com coragem de expressar publicamente posições pessoais, ou rupturas pessoais, obtidas com base em confrontos anteriores com posições pessoais e públicas de autores desconhecidos. Dentre estes autores públicos ressaltam-se os formadores de opinião dos veículos de comunicação, da imprensa livre, da televisão, que organizaram os ranqueamentos das universidades ou divulgaram classificações do Provão. Destacam-se as culturas estudantis tradicionalmente críticas às medidas de governos. Como um fiel da balança neste estudo, os estudantes mostraram-se bem informados, atentos aos processos de gestão, de melhorias e de mudanças na universidade.

Ao concluir, respondemos às formulações suscitadas por Goffman - os estudantes parecem colocar-se nos cenários de avaliação com uma fachada pessoal e uma fachada de representação coletiva, desempenhando papel de atores ao responderem provas e, como personagens, ao pensarem os processos de avaliação. Estudantes "transindivíduos", em países diferentes, parecem desenvolver uma consciência social sobre a falta de melhorias e mudanças pósavaliação. Contudo reafirmam a legitimidade e importância da avaliação das universidades.

\section{REFERÊNCIAS BIBLIOGRÁFICAS}

BACELAR, J.; FONTES, P. Valuing competences acquired in extra-curricular activities: a student's vision. In: TEACHING AND LEARNING IN HIGHER EDUCATION: new trends and innovations. Abstracts. Aveiro: Universidade de Aveiro, 2003. (International Conference, April 13-17)

BOSS, W.; TARNAI, C. University faculty member's and students perception's of university academic systems. International Journal of Educational Research, v.31, n.8, p.699-7/5, 1999.

BRASIL. Ministério da Educação. Comissão Especial. Diplomação, retenção e evasão nos cursos de graduação em IES públicas. Porto Alegre: Andifes; Abruem; MEC/Sesu, 1996. (Relatório)

ENTWISTLE, N. J.; RAMSDEN, P. Understanding student learning. London: Croom Helm, 1983. 
FELDMAN, K.; NEWCOMB, T. The Impact of college on students. San Francisco: Jossey Bass, 1976.

GENRO, M. E. et al. Representações dos estudantes sobre a avaliação das universidades na relação com o projeto acadêmico institucional. Revista Educação Unisinos, São Leopoldo, v.7, n. 13 (esp.: Anais), p. I-21, 2003.

GOFFMAN, E. A Representação do eu na vida cotidiana. 4. ed. Petrópolis: Vozes, 1989.

GOLDMANN, L. Epistemologia e filosofia política. Porto: Presença, 1984.

HABERMAS, J. Toward a rational society. Boston: Beacon Press, 1970.

JENKINS, A. et al. Teaching and research: student perspectives and policy implications. Studies in Higher Education, v.23, n.2, p. 127-141, 1998.

LATIESA, M. La Deserción universitária. Madrid: Centro de Investigaciones Sociológicas, 1992.

LECKEY, J.; NEILL, J. Quantifying quality: the importance of student feedback. Quality in Higher Education, v.7, n. I, p.19-32, 2001.

LEITE, D. Aprendizagem e consciência social na universidade. Porto Alegre, 1990. Tese (dout.) PPGEDU-UFRGS.

Aprendizagens do estudante universitário. In: LEITE, D.; MOROSINI, M. C. (orgs.) Universidade futurante: produção do ensino e inovação. 2. ed. Campinas: Papirus, 2002. p.21-37.

Metacognição e aprendizagem na universidade. Revista de Educação, Lisboa, v. 2, n. 2, p.55-64, out. 1992.

LIZZIO, A.; WILSON, K.; SIMONS, R. University students' perceptions of the learning environment and academic outcomes: implications for theory and practice. Studies in Higher education, v. 27, n. I, p.27-52, feb. 2002.

MERCURI, E.; POLYDORO, S. A. J. (orgs.) Estudante universitário: características e experiências de formação. Taubaté: Cabral; Universitária, 2003.

OLIVEIRA, J. A. B. de. Níveis de ajustamento e auto-regulação acadêmica em estudantes universitários. Aveiro, 2000. Dissert.(mestr.) Universidade de Aveiro.

POWELL, A. M.; HUNT, A.; IRVING, A. Evaluation of courses by whole student cohorts: a case study. Assessment \& Evaluation in Higher Education, v.22, n.4, p.397- 404, 1997.

SANDER, P. et al. University students' expectations of teaching. Studies in Higher Education, v.25, n.3, p.309-324, 2000. 
SANTHAMAN, E.; HICKS, O. Disciplinary, gender and course gear influences on student perceptions of teaching: explorations and implications. Teaching in Higher Education, v.7, n. I , p. $17-32,2002$.

SANTIAGO, R. Actos de resistência, ou como evitar que o "darwinismo" social académico se instale nas universidades. ADVERSO: Jornal ADUFRGS, Porto Alegre, p. I0, I a quinzena maio 2003.

SANTIAGO, R. et al. Influência da avaliação institucional na melhoria dos cursos e do ensino na universidade: a visão dos estudantes. In: REUNIÃO ANUAL DA ANPAE. Anais... Recife, 2004. p.90.

Modelos de governo, gerencialismo e avaliação institucional nas universidades. Revista Portuguesa de Educação, Minho, v. I6, n. I , p.75-99, 2003.

Promover o sucesso académico através da avaliação e intervenção na universidade. Avaliação: Revista da Rede de Avaliação Institucional da Educação Superior, v.6, n.3, p.3l-43, 200 I.

TAVARES, J.; SANTIAGO, R. A.; LENCASTRE, L. Insucesso no $1^{\circ}$ ano do ensino superior: um estudo no âmbito dos cursos de licenciatura em Ciências e Engenharia na Universidade de Aveiro. Aveiro: Universidade de Aveiro, 1998.

Recebido em: abril 2006

Aprovado para publicação em: julho 2006 